\title{
DETERMINAÇÃO DE GLICOALCALÓIDES EM BATATAS in natura (Solanum Tuberosum L.) COMERCIALIZADAS NA CIDADE DE CAMPINAS, ESTADO DE SÃO PAULO ${ }^{1}$
}

\author{
Rita Margarete D. MACHADO², Maria Cecília F. TOLEDO',*
}

\begin{abstract}
RESUMO
A batata é uma das principais hortaliças cultivadas no Brasil, constituindo-se em um dos mais importantes alimentos na dieta humana, em decorrência de sua disponibilidade e características nutricionais. Entretanto, membros da família Solanaceae produzem, durante crescimento e após colheita, compostos potencialmente tóxicos denominados glicoalcalóides, dos quais $\alpha$-solanina e $\alpha$-chaconina predominam. A concentração máxima desses compostos em batata in natura considerada segura para consumo humano é estimada em $200 \mathrm{mg} \cdot \mathrm{kg}^{-1}$, expressa como glicoalcalóides totais (GAT). No presente estudo, foram extraídos e quantificados os GAT em amostras de tubérculos de batata in natura comercializados na cidade de Campinas, SP. A técnica utilizada foi a cromatografia líquida de alta eficiência (CLAE) com coluna C18 e detetor de arranjo de diodos. O valor médio de recuperação foi 102,6\% para $\alpha$-solanina e $100,2 \%$ para $\alpha$-chaconina. Os limites de quantificação foram $2,5 \mu \mathrm{g} \cdot \mathrm{mL}^{-1}$ para $\alpha$-solanina e $1,4 \mu \mathrm{g} \cdot \mathrm{mL}^{-1}$ para $\alpha$-chaconina. As concentrações de GAT em amostras individuais de tubérculos inteiros das diferentes variedades e tipos estudados (Bintje, Monaliza, Asterix e Bolinha) variaram de 22,4 a $246,9 \mathrm{mg} \cdot \mathrm{kg}^{-1}$. Das amostras analisadas, $82 \%$ apresentaram níveis de GAT inferiores a $100 \mathrm{mg} \cdot \mathrm{kg}^{-1}$, o que indica que as variedades de batatas estudadas podem ser consideradas seguras para consumo humano.

Palavras-chave: glicoalcalóide; $\alpha$-solanina; $\alpha$-chaconina.
\end{abstract}

\section{SUMMARY}

DETERMINATION OF GLYCOALKALOIDES IN POTATO TUBERS (Solanum Tuberosum L.) MARKETED IN THE CITY OF CAMPINAS, STATE OF SÃO PAULO. Potato is included among the main horticultural crops in Brazil. Due to its broad availability and nutritional characteristics, it has been considered one of the most important components in the human diet. Nevertheless, members of the family Solanaceae produce potentially toxic compounds known as glycoalkaloids during growth and post-harvest, amongst which $\alpha$-solanine and $\alpha$ chaconine predominate. The recommended safety level for these compounds in unprocessed potato tubers for human consumption, expressed as total glycoalkaloids, is $200 \mathrm{mg} \cdot \mathrm{kg}^{-1}$. In this study, samples of potato tubers of different commercial varieties collected in the city of Campinas, State of São Paulo, were extracted and analysed for their total glycoalkaloid (TGA) content using a C18 HPLC column with a photodiode array detector. The mean recoveries of $\alpha$-solanine and $\alpha$-chaconine were $102.6 \%$ and $100.2 \%$, respectively. The limit of quantitation was $2.5 \mu \mathrm{g} \cdot \mathrm{mL}^{-1}$ for $\alpha$-solanine and $1.4 \mu \mathrm{g} \cdot \mathrm{mL}^{-1}$ for $\alpha$-chaconine. The levels of TGA in individual samples of whole tubers of different varieties and type (Bintje, Monaliza, Asterix and Bolinha), ranged from 22.4 to $246.9 \mathrm{mg} \cdot \mathrm{kg}^{-1}$. In $82 \%$ of the samples the levels of TGA were below $100 \mathrm{mg} \cdot \mathrm{kg}^{-1}$, which indicates that the studied potatoes were safe for human consumption.

Keywords: glycoalkaloid; $\alpha$-solanine; $\alpha$-chaconine; HPLC.

\section{1 - INTRODUÇÃO}

Glicoalcalóides são compostos tóxicos naturalmente presentes em todas as partes da planta de batata (Solanum tuberosum L.) e podem estar envolvidos no mecanismo de defesa da planta contra ação de insetos e microrganismos [11]. As concentrações mais elevadas destes compostos se encontram na casca dos tubérculos e em seus brotos [15, 21].

Os principais glicoalcalóides presentes em batatas são $\alpha$-solanina e $\alpha$-chaconina, ambos sendo formas glicosiladas do alcalóide esteroidal solanidina (Figura 1), e estes correspondem a 95\% ou mais dos glicoalcalóides totais [1]. A razão $\alpha$-chaconina: $\alpha$-solanina é cerca de 60:40 e a concentração resultante da soma destes dois compostos é expressa como glicoalcalóides totais (GAT) [13, 15, 20]. Os glicoalcalóides parecem ter duas ações tóxicas no organismo humano: uma sobre a acetilcolinesterase, afetando o sistema nervoso central e considerada responsável por vários dos sintomas neurológicos observados após ingestão de glicoalcalói-

\footnotetext{
1. Recebido para publicação em 06/06/2002. Aceito para publicação em 26/09/2003 (000844).

2. UNICAMP - Depto. Ciência de Alimentos - CX. Postal 6121, CEP 13083970, Campinas, São Paulo, macecil@fea.unicamp.br

*A quem a correspondência deve ser enviada.
}

des, e outra sobre as membranas celulares, causando ruptura das membranas do trato-gastrointestinal com danos hemolíticos e hemorrágicos e excesso de fluido nas cavidades corpóreas [13, 15, 20].

Alguns estudos têm associado níveis de GAT acima de $220 \mathrm{mg} \cdot \mathrm{kg}^{-1} \mathrm{com}$ alterações nas características sensoriais em batatas, incluindo sabor amargo e sensação de ardência na garganta [15, 20].

Em geral, humanos parecem ser mais sensiveis à intoxicação por glicoalcalóides do que outros animais. Através de relatos de intoxicações em humanos decorrentes do consumo de batatas, estimou-se uma dose tóxica para o homem na faixa de 2 a $5 \mathrm{mg} \cdot \mathrm{kg}^{-1}$ peso corpóreo (p.c.). Esses valores de toxicidade se comparam àqueles observados para venenos bem conhecidos, tais como estricnina ( $5 \mathrm{mg} \cdot \mathrm{kg}^{-1}$ p.c.) e arsênico $\left(8 \mathrm{mg} \cdot \mathrm{kg}^{-1}\right.$ p.c.) [15, 20].

Os glicoalcalóides foram avaliados pelo JECFA (Joint FAO/WHO Expert Committee on Food Additives) em 1992, tendo o Comitê concluído que as informações disponiveis sobre $\alpha$-chaconina e $\alpha$-solanina não eram suficientes para o estabelecimento de um valor para uma ingestão diária aceitável (IDA) e que os níveis de ocorrência natural em batatas $\left(20-100 \mathrm{mg} \cdot \mathrm{kg}^{-1}\right.$ expressos em termos de solanina e/ou chaconina) não representavam uma preocupação toxicológica [6]. 


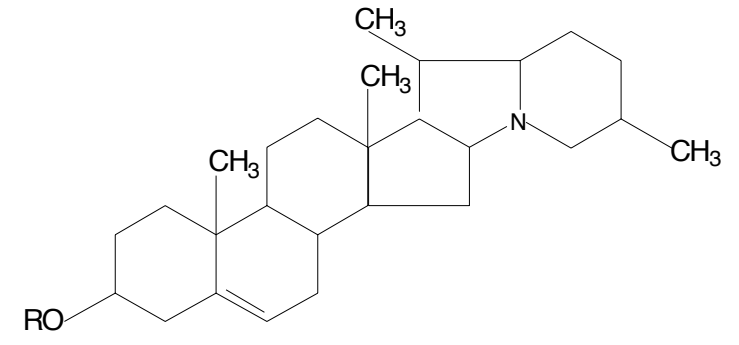

Solanidina: $\mathrm{R}=\mathrm{H}$

$\alpha$-solanina: $\mathrm{R}=\alpha$-L-ramnopiranosil- $(1 \rightarrow 2$ gal) $-\beta$-D-glicopiranosil- $(1 \rightarrow 3$ gal $)-\beta$-Dgalactopiranosil

$\alpha$-chaconina: $R=\alpha$-L-ramnopiranosil- $(1 \rightarrow 2$ gli $)-\alpha$-L-ramnopiranosil- $(1 \rightarrow 4$ gli $)-\beta$-Dglicopiranosi

FIGURA 1. Estruturas dos glicoalcalóides $\alpha$-solanina e $\alpha$ chaconina e a aglicona solanidina.

Entretanto, SLANINA [20], levando em conta o histórico de consumo de batata pelo homem e os dados de intoxicação em humanos, estimou a IDA em termos de GAT em $1 \mathrm{mg} \cdot \mathrm{kg}^{-1}$ p.c. para um adulto com peso corpóreo de 60kg. Este valor foi obtido com base numa concentração máxima na batata de $200 \mathrm{mg} \cdot \mathrm{kg}^{-1}$ e uma ingestão diária média de $300 \mathrm{~g}$ deste tubérculo.

Sabe-se que os niveis de glicoalcalóides totais podem variar em decorrência da diferenciação genética dos vários cultivares existentes, do tipo e umidade do solo, tratamentos com fertilizantes e pesticidas, poluição do ar e condições de armazenamento [7, 12, 16]. Além disso, estudos conduzidos para avaliar a estabilidade de glicoalcalóides submetidos a quatro tipos de cozimentos (microondas, fritura, assadura e fervura) indicaram que os mesmos são termoresistentes [1, 15].

Em decorrência do potencial tóxico dos glicoalcalóides e da pouca disponibilidade de dados sobre o conteúdo de $\alpha$-solanina e de $\alpha$-chaconina em batata de variedades nacionais, este trabalho teve como objetivo a determinação dos teores desses compostos em tubérculos de batatas in natura comercializados na região de Campinas, Estado de São Paulo.

\section{2 - MATERIAIS E MÉTODOS}

\section{1 - Amostragem}

Foram analisados tubérculos de batatas in natura comercializados em hipermercados, varejões e feiraslivres da cidade de Campinas. As amostras foram coletadas em diferentes locais de venda durante o período de dezoito meses, de janeiro de 2000 a junho de 2001 .

As variedades de batata analisadas foram: Bintje (com casca e sem casca), Monaliza lavada (com casca), Monaliza escovada (com casca), Asterix (com casca) e o tipo Bolinha ou Pirulito (com casca e sem casca). Analisaram-se também casca e brotos de batatas da variedade Bintje.

Os tubérculos denominados comercialmente Bolinha não constituem uma variedade de batata e sim de um tipo comercial que tem como característica básica o seu tamanho. Os tubérculos menores das diferentes variedades foram separados durante lavagem e vendidos como Bolinha ou Pirulito.

Cada amostra consistiu de 600 a 800 g de tubérculos de batata. O número de tubérculos de cada amostra foi variável em decorrência da grande heterogeneidade de tamanhos. Os tubérculos de cada amostra foram pesados e registradas as características relativas à aparência, incluindo textura (firme ou murcha), homogeneidade da cor (amarela), uniformidade no tamanho, presença de pontos pretos e de manchas esverdeadas.

\section{2 - Preparação da amostra}

Os tubérculos de batata de cada amostra foram lavados em água corrente e deixados secar em temperatura ambiente. Em seguida, foram cortados em 4 partes, sendo duas delas (correspondentes a posições opostas) fatiadas, congeladas em freezer a $-15^{\circ} \mathrm{C}$ por 24 horas e liofilizadas (Liofilizador LabConco Lyph Lock 18). Após a liofilização, as fatias foram moídas e misturadas para compor uma amostra. As amostras trituradas foram estocadas em freezer $\mathrm{a}-15^{\circ} \mathrm{C}$ até o momento da análise. O teor de água retirado durante o processo de liofilização foi verificado para cada amostra.

Para obtenção de tubérculos de batata sem casca, esta foi uniformemente retirada com faca (profundidade de $2-3 \mathrm{~mm}$ ) e, em seguida, fatiada e congelada seguindo o procedimento já descrito.

\section{3 - Extração e clarificação}

A técnica de extração utilizada foi baseada em PERCIVAL \& DIXON [17]. Pesou-se 0,5g de amostra liofilizada em tubo de centrífuga, adicionando-se em seguida $10 \mathrm{~mL}$ de solução de extração (1L de água purificada em sistema de purificação MilliQ-Plus, 20mL de ácido acético glacial, $5 g$ de bissulfito de sódio). Os tubos foram agitados durante 15 minutos e as amostras clarificadas por centrifugação (Centrífuga Hitachi himac CR 21) a 4000rpm por 20 minutos.

As análises de cada amostra foram feitas em duplicata e o valor final de concentração foi a média calculada dos dois valores de concentração encontrados.

\section{4 - Limpeza em cartucho de extração fase-sólida C18}

A limpeza do extrato clarificado em cartucho de extração fase-sólida C18 (Sep Pak C18 Plus, Waters Co) foi realizada segundo HELLENÄS \& BRANZELL [9]. Os cartuchos foram pré-condicionados com $5 \mathrm{~mL}$ de acetonitrila, seguidos por $5 \mathrm{~mL}$ de solução de extração. Foram aplicados $5 \mathrm{~mL}$ de amostra clarificada e os cartuchos foram lavados com $4 \mathrm{~mL}$ de acetonitrila:água (15:85, v/v). A eluição dos glicoalcalóides, $\alpha$-solanina e $\alpha$-chaconina, ocorreu com $4 \mathrm{~mL}$ da solução acetonitrila:tampão fosfato dibásico $\mathrm{K}_{2} \mathrm{HPO}_{4}$ 0,01M (misturaram-se 100mL de tampão fosfato dibásico 0,1M, pH ajustado para 7,6, com 300mL de água e $600 \mathrm{~mL}$ de acetonitrila). O volume final foi ajustado para $5 \mathrm{~mL}$ com a solução de eluição. Uma alíquota de $20 \mu \mathrm{L}$ foi injetada no sistema cromatográfico. 


\section{5 - Análise cromatográfica}

A técnica cromatográfica empregada para a separação de $\alpha$-solanina e $\alpha$-chaconina foi a cromatografia líquida de alta eficiência (CLAE). O sistema cromatográfico utilizado consistiu de bomba quaternária (Waters 600E Multisolvent Delivery System); detector de arranjo de diodos (Waters 996 PDA detector); injetor automático (Waters 717 Plus Autosampler) e um degaseificador de linha (Waters In-Line Degasser). A coluna analítica utilizada foi uma Hypersil ODS $5 \mu \mathrm{m}(250 \times 4,6 \mathrm{~mm})$ e a fase móvel empregada foi acetonitrila:água:etanolamina (35:65:0,05) com pH ajustado para 4,5 - 4,6 com solução de ácido ortofosfórico 10\%. O eluente foi monitorado a $200 \mathrm{~nm}$ numa vazão de $1 \mathrm{~mL} \cdot$ minuto $^{-1}$. A faixa de aquisição dos espectros foi de 190 a 400nm. Utilizou-se acetonitrila grau cromatográfico e água purificada em sistema de purificação MilliQ-Plus (Millipore). Os outros solventes utilizados foram de grau PA.

\section{6 - Quantificação e identificação dos glicoalca- lóides}

As áreas dos picos nos cromatogramas das amostras de batata foram comparadas com as áreas obtidas de análises de soluções dos padrões puros de $\alpha$-solanina $\left(\mathrm{C}_{45} \mathrm{H}_{73} \mathrm{NO}_{15}\right)$ e $\alpha$-chaconina $\left(\mathrm{C}_{45} \mathrm{H}_{73} \mathrm{NO}_{14}\right)$, adquiridos da Sigma Chemical Co. (St. Louis, EUA), dissolvidos em tampão fosfato $\mathrm{KH}_{2} \mathrm{PO}_{4}$ 0,05M. Para tanto, foram utilizadas curvas de calibração externa em sete niveis de concentrações para a quantificação dos compostos de interesse ( $\alpha$-solanina e $\alpha$-chaconina), sendo que cada padrão foi injetado três vezes no sistema cromatográfico. Os calibradores (padrões dissolvidos em solução tampão $\mathrm{KH}_{2} \mathrm{PO}_{4} 0,05 \mathrm{M}$ ) foram mantidos em temperatura de aproximadamente $5^{\circ} \mathrm{C}$ e utilizados durante o período máximo de três meses, conforme indicação de HELLENÄS \& BRANZELL [9].

A concentração dos padrões variou de 0,7 a $61 \mu \mathrm{g} \cdot \mathrm{mL}^{-1}$ para $\alpha$-solanina e de 0,8 a $64 \mu \mathrm{g} \cdot \mathrm{mL}^{-1}$ para $\alpha$-chaconina, correspondendo a teores em batata in natura de 2,9 a $244 \mathrm{mg} \cdot \mathrm{kg}^{-1}$ e 3,0 a $256 \mathrm{mg} \cdot \mathrm{kg}^{-1}$ para $\alpha$-solanina e $\alpha$-chaconina, respectivamente.

A identificação dos picos nos cromatogramas das amostras analisadas foi feita por comparação com o tempo de retenção e com espectros dos padrões de $\alpha$-solanina e $\alpha$-chaconina.

\section{7 - Validação de metodologia}

Em face da não disponibilidade de amostras certificadas, a exatidão do método foi calculada através dos valores de recuperação obtidos a partir das análises de amostras fortificadas. Os padrões foram adicionados nas amostras liofilizadas antes da adição da solução de extração, em quantidades equivalentes em batata in natura de 21,1 - 64,7mg. $\mathrm{kg}^{-1}$ para $\alpha$-solanina, e de 19,0 $59,1 \mathrm{mg} \cdot \mathrm{kg}^{-1}$ para $\alpha$-chaconina. A repetibilidade da recuperação, realizada para o maior nivel de fortificação, foi obtida através das análises de uma mesma amostra em dias diferentes.
A fim de verificar a repetibilidade do método, foram realizadas oito determinações em uma única amostra em um mesmo dia, e calculados o desvio padrão e coeficiente de variação. Subseqüentemente, a amostra controle foi analisada durante o decorrer do experimento.

Os limites de detecção e quantificação foram obtidos de acordo com MILLER \& MILLER [14], utilizando dados da regressão da curva de calibração montada para quantificação dos compostos de interesse. Como no decorrer do trabalho várias curvas de calibração foram construídas, os valores finais dos limites de detecção e quantificação foram considerados como sendo as medianas dos limites calculados com as diferentes curvas de calibração, conforme proposto por CURRIE [5].

\section{3 - RESULTADOS E DISCUSSÃO}

A média do teor de água retirado das amostras pelo processo de liofilização variou de 75,0 a $88,3 \%$, valores estes utilizados nos cálculos de concentração dos glicoalcalóides $\alpha$-solanina e $\alpha$-chaconina.

Os valores médios de recuperação foram 102,6\% e $100,2 \%$ para $\alpha$-solanina e $\alpha$-chaconina, respectivamente. Os coeficientes de variação $(\mathrm{CV})$ das médias de recuperação foram condizentes com a literatura, que sugere para estudos de recuperação CV inferior a 15\% e médias de concentração obtida com variação máxima de $20 \%$ [3, 4].

A repetibilidade da recuperação, avaliada através dos resultados obtidos de amostras fortificadas com um mesmo nível de adição de padrões e analisadas em dias diferentes $(n=6)$, resultou em valores de $\mathrm{CV}$ iguais a 3,0\% para $\alpha$-solanina e $8,8 \%$ para $\alpha$-chaconina.

A precisão do método, avaliada durante todo o período analítico através de uma amostra controle $(n=7)$, apresentou coeficiente de variação de 9,7 e 7,1\% para $\alpha$-solanina e $\alpha$-chaconina, respectivamente. Estes valores estão abaixo do valor limite de $15 \%$ sugerido por HORWITZ, KAMPS \& BOYER [10] para compostos presentes em alimentos em níveis de ppm.

Os limites de quantificação obtidos para $\alpha$-solanina e $\alpha$-chaconina foram $2,5 \mu \mathrm{g} \cdot \mathrm{mL}^{-1}$ e $1,4 \mu \mathrm{g} \cdot \mathrm{mL}^{-1}$, e os limites de detecção foram $0,8 \mu \mathrm{g} \cdot \mathrm{mL}^{-1}$ e $0,4 \mu \mathrm{g} \cdot \mathrm{mL}^{-1}$, respectivamente.

A resposta do detector foi linear na faixa de $0,7 \mu \mathrm{g} \cdot \mathrm{mL}^{-1}$ a $61 \mu \mathrm{g} \cdot \mathrm{mL}^{-1}$ para $\alpha$-solanina e de $0,8 \mu \mathrm{g} \cdot \mathrm{mL}^{-1}$ a $64 \mu \mathrm{g} \cdot \mathrm{mL}^{-1}$ para $\alpha$-chaconina. Estas faixas de concentração compreendem o limite de quantificação, bem como a concentração mais alta utilizada nas curvas de calibração. Todas as curvas de calibração apresentaram, até o nível de concentração mais alto, valores do coeficiente de Pearson (r) acima de 0,999.

Os picos dos compostos $\alpha$-solanina e $\alpha$-chaconina nos cromatogramas das amostras analisadas apresentaram adequada separação e resolução em comparação com os picos dos padrões, conforme pode ser observado na Figura 2. 

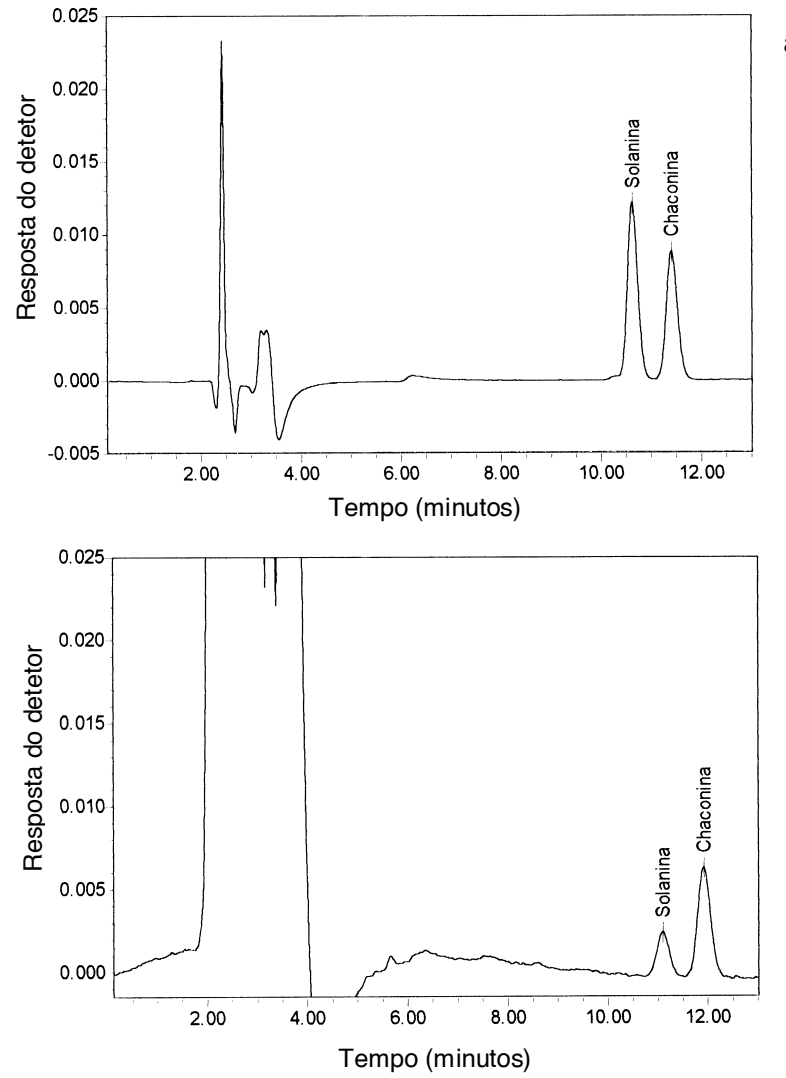

FIGURA 2. Cromatogramas: a) padrões $\alpha$-solanina e $\alpha$-chaconina; b) extrato de amostra de tubérculo inteiro de batata in natura da variedade Monaliza lavada. Condições de análise: Coluna Hypersil ODS $5 \mu \mathrm{m}$ (250 x 4,6mm); fase móvel: acetonitrila:água:etanolamina (35:65:0,05; v/v/v), $\mathrm{pH}$ 4,5 - 4,6 ajustado com ácido ortofosfórico 10\%; vazão de $1 \mathrm{~mL} \cdot \mathrm{min} .^{-1}$; leitura a 200nm.

A Tabela 1 mostra os resultados obtidos das análises das amostras de batata coletadas em diferentes locais de venda durante o período de dezoito meses, compreendendo janeiro de 2000 a junho de 2001 .

TABELA 1. Teor de glicoalcalóides totais (GAT) ( $\alpha$-solanina $+\alpha$-chaconina) em amostras de tubérculos de batata com casca.

\begin{tabular}{|c|c|c|c|c|c|c|}
\hline \multirow{2}{*}{$\begin{array}{l}\text { Variedade / } \\
\text { Tipo }\end{array}$} & \multirow[t]{2}{*}{$N$} & \multirow{2}{*}{$\begin{array}{c}\alpha \text {-Solanina } \\
\left(\mathrm{mg} \cdot \mathrm{kg}^{-1}\right) \\
\text { Mín. - Máx. }\end{array}$} & \multirow{2}{*}{$\begin{array}{c}\alpha \text {-Chaconina } \\
\left(\mathrm{mg} \cdot \mathrm{kg}^{-1}\right) \\
\text { Mín. - Máx. }\end{array}$} & \multicolumn{2}{|c|}{$\begin{array}{c}\text { GAT } \\
\left(\mathrm{mg} \cdot \mathrm{kg}^{-1}\right)\end{array}$} & \multirow{2}{*}{$\begin{array}{l}\text { CV } \\
(\%)\end{array}$} \\
\hline & & & & Mín. - Máx. & Média \pm D.P. & \\
\hline Bintje & 7 & $7,5-30,3$ & $25,6-65,0$ & $33,1-95,3$ & $59,6 \pm 20,9$ & $1,5-7,3$ \\
\hline Bolinha & 9 & $22,8-88,1$ & $38,4-158,8$ & $61,2-246,9$ & $112,4 \pm 55,5$ & $0,7-10,1$ \\
\hline $\begin{array}{l}\text { Monaliza } \\
\text { (lavada) }\end{array}$ & 12 & $4,6-31,3$ & $17,8-69,5$ & $22,4-100,8$ & $63,9 \pm 23,3$ & $0,2-7,3$ \\
\hline $\begin{array}{l}\text { Monaliza } \\
\text { (escovada) }\end{array}$ & 04 & $10,9-46,0$ & $28,1-83,1$ & $39,0-129,1$ & $80,3 \pm 40,1$ & $0,1-10,5$ \\
\hline Asterix & 02 & $19,7-31,0$ & $42,6-74,6$ & $62,0-105,6$ & $84,0 \pm 30,6$ & 0,2 \\
\hline
\end{tabular}

As concentrações de glicoalcalóides totais (GAT) em amostras individuais de tubérculos inteiros das diferentes variedades e tipos estudados (Bintje, Monaliza,
Bolinha e Asterix) variaram de 22,4 a $246,9 \mathrm{mg} \cdot \mathrm{kg}^{-1}$. A maioria das amostras analisadas (82\%) apresentou teor de glicoalcalóides totais inferior a $100 \mathrm{mg} \cdot \mathrm{kg}^{-1}$, independentemente da variedade/tipo e do tamanho do tubérculo. Estes valores estão dentro da faixa de concentração de GAT relatada pela literatura para outras variedades de batata comercializadas no Brasil [22].

A razão entre $\alpha$-chaconina e $\alpha$-solanina nas diferentes amostras variou de 57:43 a 80:20. A importância de se conhecer a razão entre estes glicoalcalóides fundamenta-se em estudos que indicam que o potencial tóxico de $\alpha$-chaconina é maior do que o de $\alpha$-solanina $[2,8,18]$. Em estudos de rupturas de membranas por $\alpha$-solanina e $\alpha$-chaconina, RODDICK, RIJNEMBERG \& OSMAN [19] identificaram uma interação sinergética entre estes glicoalcalóides, sugerindo que as proporções relativas destes glicoalcalóides podem influenciar sua toxicidade mais do que as concentrações absolutas dos glicoalcalóides totais.

O valor de GAT em batata de $200 \mathrm{mg} \cdot \mathrm{kg}^{-1}$, estimado por SLANINA [20] como limite máximo recomendado, foi excedido por uma única amostra, do tipo Bolinha, que continha $246,9 \mathrm{mg} \cdot \mathrm{kg}^{-1}$. Esta amostra apresentou tubérculos com peso ao redor de $15 \mathrm{~g}$, com pontos pretos, manchas verdes em sua superfície e murchamento.

De acordo com os gráficos da Figura 3 verifica-se que, além de uma acentuada variação nos teores de glicoalcalóides totais entre as diferentes variedades, houve diferenças marcantes entre amostras de uma mesma variedade, evidenciando uma grande variabilidade individual nos níveis destes compostos em batatas.

Para a maioria das amostras, obteve-se uma relação inversa entre tamanhos de tubérculos de batata e teor de glicoalcalóides totais. No caso da variedade Bintje, o peso médio dos tubérculos variou de 72 a $145 \mathrm{~g}$, sendo que a concentração de GAT para os respectivos tamanhos foi $95,3 \mathrm{mg} \cdot \mathrm{kg}^{-1}$ e $33,1 \mathrm{mg} \cdot \mathrm{kg}^{-1}$. O mesmo foi observado para a variedade Monaliza lavada, sendo que neste caso a concentração de GAT foi $46,6 \mathrm{mg} \cdot \mathrm{kg}^{-1}$ para os tubérculos de maior tamanho $(212 \mathrm{~g})$ e $100,8 \mathrm{mg} \cdot \mathrm{kg}^{-1}$ para os tubérculos de menor tamanho (70g).

TABELA 2. Aspecto visual dos tubérculos analisados e teor de glicoalcalóides totais (GAT).

\begin{tabular}{lcccc}
\hline \multirow{2}{*}{ Variedade / Tipo } & \multicolumn{5}{c}{ Descrição } \\
\cline { 2 - 5 } & $\begin{array}{l}\text { Características homogêneas de } \\
\text { forma, cor amarelada da casca } \\
\text { e textura firme }\end{array}$ & $\begin{array}{l}\text { Heterogeneidade na forma, } \\
\text { pontos pretos, casca } \\
\text { esverdeada e textura murcha }\end{array}$ \\
\hline Bintje & $\mathrm{n}$ & $\mathrm{GAT}\left(\mathrm{mg}^{\mathrm{k}} \mathrm{kg}^{-1}\right)$ & $\mathrm{n}$ & $\mathrm{GAT}\left(\mathrm{mg}^{-1} \mathrm{~kg}^{-1}\right)$ \\
Bolinha & 4 & $33,1-61,7$ & 3 & $65,6-95,3$ \\
Monaliza lavada & 4 & $61,2-91,8$ & 5 & $81,4-246,9$ \\
Monaliza escovada & 8 & $22,4-88,7$ & 4 & $45,7-100,8$ \\
Asterix & 1 & 39 & 3 & $57,9-129,1$ \\
\hline
\end{tabular}

$\mathrm{n}=$ número de coletas

Acredita-se que esta relação inversa entre tamanho e concentração não tenha sido mantida para todas as amostras analisadas de uma mesma variedade em 
face ao estado em que o tubérculo se encontrava. Amostras de tubérculos de batata de uma mesma variedade, mas que apresentavam forma heterogênea, pontos pretos, casca esverdeada e textura murcha, apresentaram maiores concentrações de glicoalcalóides totais em relação a tubérculos com pesos inferiores, mas que apresentavam características homogêneas de forma, cor amarelada da casca e textura firme (Tabela 2).

$$
\square \text { Bintje }
$$

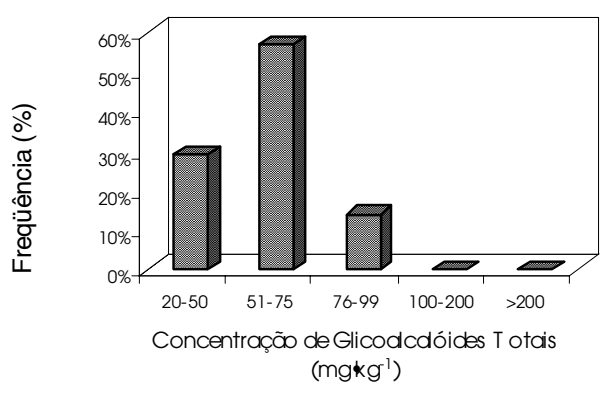

$\square$ Monaliza lavada
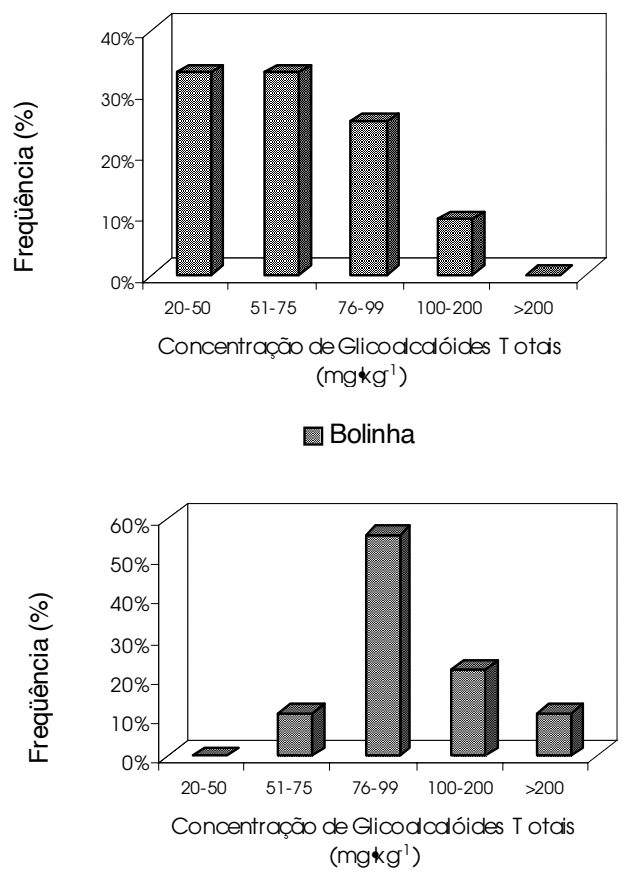

$\square$ Monaliza escovada

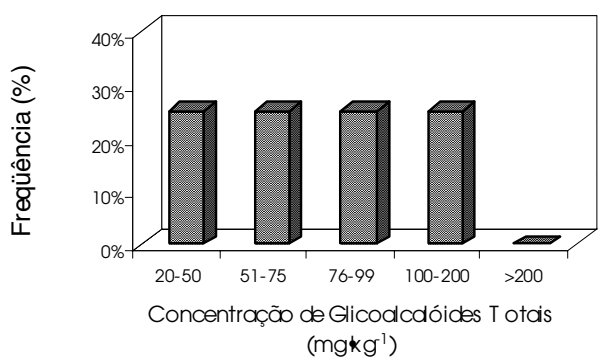

FIGURA 3. Distribuição da frequência (\%) dos níveis de glicoalcalóides totais ( $\alpha$-solanina $+\alpha$-chaconina) para cada variedade e tipo de batata analisada.
O teor de GAT das amostras de batata da variedade Bintje e tipo Bolinha analisadas sem a casca foi 14,7 e $3,7 \mathrm{mg} \cdot \mathrm{kg}^{-1}$, respectivamente. Quando analisadas com a casca, o teor de GAT foi $61,7 \mathrm{mg} \cdot \mathrm{kg}^{-1}$ para a variedade Bintje e $61,2 \mathrm{mg} \cdot \mathrm{kg}^{-1}$ para o tipo Bolinha, o que confirma a maior concentração de glicoalcalóides na casca relativamente à polpa. Casca e brotos de tubérculos da variedade Bintje apresentaram níveis de GAT de $342 \mathrm{mg} \cdot \mathrm{kg}^{-1} \mathrm{e}$ $1.370 \mathrm{mg} \cdot \mathrm{kg}^{-1}$, respectivamente, o que comprova a maior concentração de $\alpha$-solanina e $\alpha$-chaconina na região periférica dos tubérculos de batata.

\section{4 - CONCLUSÕES}

Os resultados apresentados indicam que:

1 - A concentração de glicoalcalóides totais (GAT) em batatas depende da variedade e do tamanho do tubérculo. Para tubérculos de uma mesma variedade e de peso semelhante, o teor de GAT varia em função da textura, cor e presença de pontos pretos: tubérculos murchos, de cor esverdeada e com pontos pretos tendem a apresentar níveis mais elevados de glicoalcalóides.

2 - Os teores de glicoalcalóides totais de batatas das variedades Bintje, Monaliza lavada, Monaliza escovada e Asterix comercializadas na região de Campinas são inferiores à concentração máxima recomendada como segura para consumo humano.

\section{5 - REFERÊNCIAS BIBLIOGRÁFICAS}

[1] BUSHWAY, R.J.; PONNAMPALAM, R. $\alpha$-Chaconine and $\alpha$-solanine content of potato products and their stability during several modes of cooking. J. Agri. Food Chem., v. 29 , n. 4 , p. 814-817, 1981.

[2] CALDWELl, K.A.; GROSJEAN, O.K.; HENIKA, P.R.; FRIEDMAN, M. Hepatic ornithine decarboxylase induction by potato glycoalkaloids in rats. Food Chem. Toxico1., v. 29, n. 8, p. 531-535, 1991.

[3] CHASIN, A.A.M.; CHASIN, M.; SALVADORI, M.C. Validação de métodos em análises toxicológicas. Rev. Farm. Bioquím. Univ. S. Paulo, v. 30, n. 2, p. 49-53, 1994.

[4] CHASIN, A.A.M.; NASCIMENTO, E.S.; RIBEIRO-NETO, L.M.; SIQUEIRA, M.E.P.B.; ANDRAUS, M.H.; SALVADORI, M.C.; FERNÍCOLA, N.A.G.; GORNI, R.; SALCEDO, S. Validação de métodos em análises toxicológicas: uma abordagem geral. Rev. Bras. Toxicol., v. 11, n. 1, p.1-6, 1998.

[5] CURRIE, L.A. Detection and quantification limits: origins and historical overview. Anal. Chim. Acta, v. 391, n. 2, p. 127-134, 1999.

[6] FAO/WHO. 1999. Summary of evaluations performed by the Joint FAO/WHO Expert Committee on Food Additives (JECFA). ILSI Press.

[7] FRIEDMAN, M.; DAO, L. Distribution of glycoalkaloids in potato plants and commercial potato products. $\mathbf{J}$. Agri. Food Chem., v. 40, n. 3, p.419-423, 1992.

[8] FRIEDMAN, M.; RAYBURN, J.R.; BANTLE, J.A. Developmenal toxicology of potato alkaloids in the frog embryo teratogenesis assay - Xenopus (FETAX Food Chem. Toxicol., v. 29, n. 8, p. 537-547, 1991.

[9] HELLENÄS, K.E.; BRANZELL, C. Liquid chromatographic determination of the glycoalkaloids $\alpha$-solanine and $\alpha$ - 
chaconine in potato tubers: NMKL interlaboratory study. J. AOAC Int., v. 80, n. 3, p. 549-554, 1997

[10] HORWITZ, W.; KAMPS, L.R.; BOYER, K.W. Quality assurance in the analysis of foods for trace constituents. J. Assoc. Off Anal Chem., v. 63, n. 6, p. 1344-1354, 1980.

[11] JADHAV, S.J.; LUTZ, S.E.; MAZZA, G.; SALUNKHE, D.K. Potato Glycoalkaloids: chemical, analytical, and biochemical perspectives. ACS Symposium Series, v. 662, p. 94-114, 1997

[12] JADHAV, S.J.; SALUNKHE, D.K. Formation and control of clorophyll and glycoalkaloids in tubers of Solanum tuberosum L. and evaluation of glycoalkaloid toxicity. Adv. Food Res., v. 21, p. 307-354, 1975.

[13] MAGA, J.A. Potato glycoalkaloids. CRC Crit. Rev. Food Sci. Nutr., v. 12, n. 4, p. 371-405, 1980.

[14] MILLER, J.C.; MILLER, J.M. Errors in instrumental analysis: regression and correlation. In: Miller JC, Miller JM. Statistics for analytical chemistry. 3rd ed. Chichester: Ellis Horwood. p.101-141, 1993.

[15] MORRIS, S.C.; LEE, T.H. The toxicity and teratogenicity of Solanaceae glycoalkaloids, particularly those of the potato (Solanum tuberosum): a review. Food Technol. Aust, v. 36, n. 3, p. 118-124, 1984.

[16] PATIL, B.C.; SALUNKHE, D.K.; SINGH, B. Metabolism of solanine and chlorophyll in potato tubers as affected by light and specific chemicals. J. Food Sci., v. 36, n. 3, p. 474-476, 1971.
[17] PERCIVAL, G.; DIXON, G.R. Glycoalkaloid concentrations in aerial tubers of potato (Solanum tuberosum L.). J. Sci. Food Agri., v. 70, n. 4, p. 439-448, 1996.

[18] RAYBURN, J.R.; BANTLE, J.A.; FRIEDMAN, M. Role of carbohydrate side chains of potato glycoalkaloids in developmental toxicity. J. Agri. Food Chem., v. 42, n. 7, p. 1511-1515, 1994.

[19] RODDICK, J.G.; RIJNENBERG, A.L.; OSMAN, S.F. Synergistic interaction between potato glycoalkaloids $\alpha$-solanine and $\alpha$-chaconine in relation to destabilization of cell membranes: Ecological implications. J. Chem Ecol., v. 14, n. 3, p. 889-902, 1988.

[20] SLANINA, P. Solanine (glycoalkaloids) in potatoes: toxicological evaluation. Food Chem. Toxicol., v. 28, n. 11, p. 759-761, 1990.

[21] SMITH, D.B.; RODDICK, J.G.; JONES, J.L. Potato glycoalkaloids: some unanswered questions. Trends Food Sci. \& Technol., v. 7, n. 4, p. 126-131, 1996.

[22] SPOLADORE, D.S.; TEIXEIRA, J.P.F.; ZULLO, M.A.T.; TEIXEIRA, P.R.M.; COELHO, S.M.B.M.; MIRANDA, F.H.S. Ocorrência de glicoalcalóides e esverdeamento em tubérculos de batata recém-colhidos e armazenados. Bragantia, v. 42, p. 221-231, 1983.

\section{6 - AGRADECIMENTOS}

À FAPESP (Fundação de Amparo à Pesquisa do Estado de São Paulo) pelo suporte financeiro obtido através da concessão de bolsa e recursos de reserva técnica (processo n. 99/08476-5). 